\title{
UK-2A, B, C and D, Novel Antifungal Antibiotics from Streptomyces sp. 517-02
}

\section{Comparative Studies of UK-2A with Antimycin $A_{3}$ on Cytotoxic Activity and Reactive Oxygen Species Generation in LLC-PK1 Cells}

\author{
Hiroaki Takimoto, Kiyotaka Machida, Masashi Ueki ${ }^{\dagger}$, Toshio TanaKa \\ and MaKoto TANigUCH* \\ Department of Biology, Graduate School of Science, Osaka City University, \\ 3-3-138 Sugimoto, Sumiyoshi-ku, Osaka 558-8585, Japan \\ (Received for publication February 9, 1999)
}

\begin{abstract}
UK-2A, a novel antifungal antibiotic, is a structural relative of antimycin $A_{3}$ (AA) and its mode of action is similar to that of AA which inhibits mitochondrial electron transport at complex III. In spite of their structural resemblance, AA had strong cytotoxicity while UK-2A had little cytotoxicity against LLC-PK 1 cells as well as other types of cultured cells. When cells were treated with UK-2A or with AA the intracellular ATP content decreased significantly within 5 minutes in glucose-free medium to almost the same extent in both cases. Moreover, under the same conditions, UK-2A killed cells at a similar rate to AA. This suggested that UK-2A entered into the cells and, like AA, inhibited mitochondrial electron transport. On the other hand, AA stimulated reactive oxygen species (ROS) production within 5 minutes even at a low concentration of $1 \mu \mathrm{M}$ whereas UK-2A did not show such an effect. The difference in the ROS-producing abilities of UK-2A and AA may account for the different cytotoxic effects of the two compounds.
\end{abstract}

UK-2A was one of the novel antifungal antibiotics isolated from Streptomyces sp. 517-02. Its structure is very similar to that of antimycin $A_{3}$ (AA). ${ }^{1 \sim 3}$ ) Moreover, both compounds inhibit electron transport at complex III in mitochondria from both yeast and rat liver ${ }^{4}$. UK-2A shows very weak cytotoxicity whereas AA is toxic to various kinds of cultured cells, besides being an antibiotic, an insecticide, and a miticide ${ }^{5}$.

Our previous report suggested that the low cytotoxicity of UK-2A was due to its limited penetration of the cell membrane ${ }^{4)}$.

Recent studies have indicated that the cytotoxic activity of AA relates to programmed cell death (PCD) such as apoptosis ${ }^{6)}$ and secondary necrosis, associated with production of reactive oxygen species $(\operatorname{ROS})^{7}$, activation of caspases ${ }^{8)}$, de novo synthesis of ceramide ${ }^{9)}$ and release of cytochrome $c$ into cytosol. ${ }^{10}$ )
We wish to report here that UK-2A can penetrate the membrane of cultured cells and inhibit mitochondrial electron transport, but there is a difference between UK-2A and AA with respect to ROS production, which is the most rapid event considered as the trigger of PCD in LLC-PK 1 cells.

\section{Materials and Methods}

\section{Chemicals}

Antimycin $\mathrm{A}_{3}$ and luciferin-luciferase were from Sigma Chemical Co., 2', $7^{\prime}$-dichlorofluorescein diacetate (DCFH-DA) from Acros Organics. Others were commercially available.

$\dagger$ Present address: Laboratory of Antibiotics, The Institute of Physical and Chemical Research (RIKEN), 2-1, Hirosawa, Wako-shi, Saitama 565-0871, Japan. 


\section{Cell Cultures}

Porcine renal proximal tubule cells (LLC-PK1) were obtained from the American Type Culture Collection (CRL 1392; ATCC, Rickville, MD). Cells were regularly grown in $90 \mathrm{~mm}$ culture dishes and maintained in a medium composed of Dulbecco's modified Eagle's medium (DMEM; GIBCO Laboratories, Grand Island, $\mathrm{NY}$ ), 10\% heat-inactivated bovine serum and $3.7 \mathrm{~g} /$ liter of $\mathrm{NaHCO}_{3}$. Cultures were maintained in a humidified incubator gassed with $5 \% \mathrm{CO}_{2}-95 \%$ air at $37^{\circ} \mathrm{C}$ and fed at intervals of $24 \sim 72$ hours. All experiments were performed the day follows cell plating.

\section{Cytotoxic Activities in DMEM}

Cytotoxicity of UK-2A and antimycin A were determined using the MTT calorimetric method ${ }^{11)}$ with minor modification. Briefly, cells were seeded in a 96-well plate and incubated for 24 hours in $100 \mu$ of DMEM containing the appropriate amount of UK-2A or AA. At the end of the incubation period, $20 \mu \mathrm{l}$ of MTT solution $(5 \mathrm{mg} / \mathrm{ml}$ in Phosphate Buffered Saline (PBS)) was added and further incubated for 2 hours at $37^{\circ} \mathrm{C}$. After removing supernatant, cells were washed with PBS 2 times and the reduced form of MTT was extracted with isopropanol containing $0.1 \% \mathrm{HCl}$. The amount of extracted, reduced form of MTT was measured by absorbance at $570 \mathrm{~nm}$ using a Shimadzu UV-200 spectrophotometer.

\section{Time Course of Cell Death in Glucose-free DMEM}

Cells $\left(1 \times 10^{5}\right)$ were plated in $35 \mathrm{~mm}$ culture dishes, washed with glucose-free DMEM and exposed to UK$2 \mathrm{~A}$ or $\mathrm{AA}$ in the same medium for indicated times. At the end of the incubation period, cells were trypsinized and collected by centrifugation.

Cell death was determined using the trypan blue dye exclusion method ${ }^{12)}$. Cells failing to exclude the dye were considered to be non-viable. Dead cells were counted with Hepatocytometer (Erma Tokyo 1/10 mm deep). Experiments were performed in triplicate and the values recorded are means \pm standard deviations.

Determination of Intracellular ATP Content in Glucose-free DMEM

Cells $\left(5 \times 10^{5}\right)$ were plated in $60 \mathrm{~mm}$ culture dish, washed with glucose-free DMEM and incubated with $\mathrm{UK}-2 \mathrm{~A}$ or $\mathrm{AA}$ for an appropriate time in the same medium. After removing the supernatants, the cells were solubilized by addition of $1.5 \mathrm{ml}$ of $0.14 \mathrm{~N} \mathrm{HNO}_{3}$ at $70^{\circ} \mathrm{C}$. The incubation was continued for an additional 20 minutes at $37^{\circ} \mathrm{C}$ to allow complete solubilization. The supernatants were collected and centrifuged for 10 minutes at $3,000 \times g$. The $\mathrm{pH}$ of the supernatant was adjusted to $\mathrm{pH} 7.0$ by adding $0.6 \mathrm{~N} \mathrm{NaOH}$ in $20 \mathrm{~mm}$ Tris ${ }^{13)}$.

The ATP content was determined using the LuciferinLuciferase ( $\mathrm{L} /$ Lase) reaction by counting light emission in a liquid scintillation counter (Beckman LC-6500) on the single photon mode ${ }^{14)}$. ATP content is expressed as percent of control. The concentrations of ATP content in control cells were $4.78 \mathrm{nmol} / \mathrm{ml} / 10^{5}$ cells before incubation and $5.90 \mathrm{nmol} / \mathrm{ml} / 10^{5}$ cells after 60 minutes incubation. Experiments were performed three times and the values are means \pm standard deviations.

Measurement of Production of ROS in Glucose-free DMEM

The intracellular generation of ROS was examined using DCFH-DA. This probe measures the generation of $\operatorname{ROS}^{15)}$. Cells $\left(1 \times 10^{5}\right)$ were introduced to a 24-well plate. After removing the culture medium, the cells were washed with glucose-free modified Gey's buffer $(\mathrm{MGB})^{16)}$ and incubated with $\mathrm{MGB}$ containing $20 \mu \mathrm{M}$ DCFH-DA for 60 minutes at $37^{\circ} \mathrm{C}$. After the incubation period, each well was washed, and $1 \mathrm{ml}$ of $\mathrm{MGB}$ was added. Cells were treated with $10 \mu \mathrm{M}$ UK-2A or AA for different time intervals. At the end of each incubation period, fluorescence intensity of the cell was read using a Cytoflow 2300 (Millipore. Ltd.) with excitation at $488 \mathrm{~nm}$ and emission at $525 \mathrm{~nm}$. Experiments were performed three times and the values are means \pm standard deviations.

\section{Results and Discussion}

As previously described, UK-2A is a structural relative of antimycin $\mathrm{A}_{3}$ (Fig. 1). The differences in their structures was account for significant differences in biological properties ${ }^{1)}$. Table 1 shows cytotoxic effect of UK-2A and AA on several types of cultured cells. UK-2A had little cytotoxicity against LLC-PK 1 cells as well as other cells reported previously. ${ }^{1)}$ AA was cytotoxic even at very low concentrations. This could be attributed to the limited permeability of UK-2A to the cell membrane.

To investigate this problem, intracellular ATP content was measured in glucose-free DMEM. As shown in Fig. 2 , it decreased significantly after 5 minutes exposure to $10 \mu \mathrm{M}$ of UK-2A. After 30 minutes exposure, it reached the same level as for cells treated with AA. Similar effects 
Fig. 1. Structures of UK-2A and AA.<smiles>COc1ccnc(C(=O)NNC2COC(=O)C(Cc3ccccc3)C(OC(=O)C(C)C)C(C)OC2=O)c1O</smiles>

UK-2A<smiles>CCCCC1C(=O)OC(C)C(NC(=O)c2cccc(NC=O)c2O)C(=O)OC(C)C1OC(=O)CC(C)C</smiles>

AA were observed at lower concentrations by both inhibitors (data not shown). Under glucose-free condition, ATP depletion is widely used as the indicator of the inhibition of electron transport. These cells completely consumed ATP, suggesting that UK-2A can penetrate the cell memtrane and inhibit the mitochondrial electron transport as well as AA does. In DMEM, ATP content in cells treated with both inhibitors remained $80 \%$ of the control until 30 minutes. This remaining ATP may be from fermentative production of glucose (data not shown).

In glucose-free DMEM with the addition of $10 \mu \mathrm{M}$ of UK-2A or AA, cells probably die of ATP deprivation. Many studies suggest that cell death caused by AA relates to the activation of cell death program in addition to less ATP content. ${ }^{7 \sim 11}$ )

Fig. 3 shows the time course of cell death induced by UK-2A and AA in glucose-free DMEM. UK-2A killed cells almost as effectively as AA. After 2 hours exposure to UK-2A and AA, significant injury of the cells was observed under light microscope in contrast to control cells as previously described ${ }^{17}$ (data not shown).

Furthermore, the effects of UK-2A and AA on ROS generation in LLC-PK1 cells were examined. Fig. 4A shows that UK-2A did not stimulate ROS generation at an effective concentration of $10 \mu \mathrm{M}$ (Fig. 2 and 3). By contrast, AA stimulated ROS generation even at $1 \mu \mathrm{M}$ and the effect was dose dependent. Fig 4. B shows the time course of ROS generation. AA rapidly stimulated ROS generation, whereas UK-2A didn't show such effect.

ROS generation in cells treated with AA is consistent with the previous description ${ }^{8)}$. ROS causes lipid peroxidation $^{18)}$, DNA injury ${ }^{19)}$, and acts as a signal in
Table 1. Cytotoxic activities of UK-2A and AA.

\begin{tabular}{lcc}
\hline & \multicolumn{2}{c}{$\mathrm{IC}_{50}(\mu \mathrm{g} / \mathrm{ml})$} \\
\cline { 2 - 3 } & $\mathrm{UK}-2 \mathrm{~A}$ & $\mathrm{AA}$ \\
\hline $\mathrm{p}-388$ & 100 & 0.015 \\
$\mathrm{~B}-16$ & 100 & 0.02 \\
$\mathrm{~KB}$ & 17 & 0.063 \\
$\mathrm{COLO} 201$ & 35 & 0.018 \\
3T3 & 100 & 15 \\
LLC-PK1 & 100 & 0.10 \\
\hline
\end{tabular}

$\mathrm{PCD}^{20)}$. Of the events following the exposure to $\mathrm{AA}$ in glucose-free DMEM, ROS generation is the most rapid one $^{7 \sim 10)}$. Therefore, ROS generated by AA treatment may trigger the cell death program. The cells treated with AA show the necrotic form of cell death. In addition, some apoptotic features are observed in these cells; these include caspase- 1 activation, the protective effect on cell death by caspase- 3 inhibitor ${ }^{8)}$ and DNA fragmentation $^{21)}$. However, UK-2A did not stimulate ROS generation in LLC-PK 1 cells.

Complex III of the mitochondrial respiratory chain generates $\operatorname{ROS}^{22)}$, and both UK-2A and AA are complex III inhibitors. The proton motive ubiquinone cycle model (Q-cycle model) of electron flow in the mitochondrial respiratory chain shows that there are two major sites for antibiotic binding in complex III namely the ubiquinone reducing site (Qi) and the ubiquinol oxidizing site (Qo $)^{23)}$. Binding of antibiotics to Qi center of the 
Fig. 2. Effects of UK-2A and AA on intracellular ATP content in LLC-PKl cells in glucose-free DMEM.

$\bigcirc 10 \mu \mathrm{M} U K-2 \mathrm{~A}, \quad 10 \mu \mathrm{M} \mathrm{AA}$.

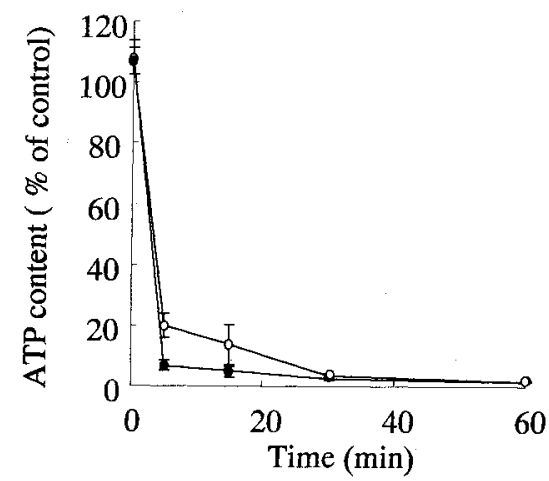

Fig. 3. Time course of LLC-PK1 cell death induced by UK-2A and $A A$ in glucose-free DMEM.
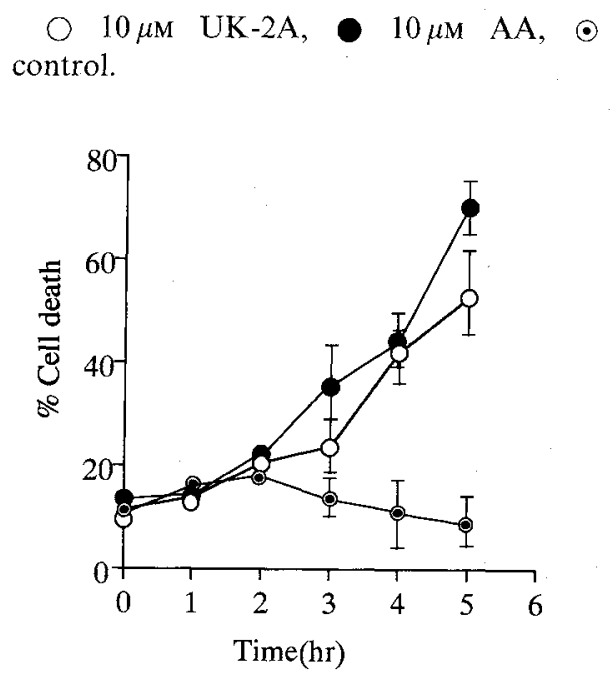

Fig. 4. Effects of UK-2A and AA on ROS generation in LLC-PK1 cells in glucose-free DMEM.

(A) Dose dependency of ROS generation affected by UK-2A and AA. O UK-2A, AA.

(B) Time course of ROS generation affected by UK-2A and AA. $\bigcirc 10 \mu \mathrm{M}$ UK-2A, $10 \mu \mathrm{M} \mathrm{AA}, \odot$ control.

(A)

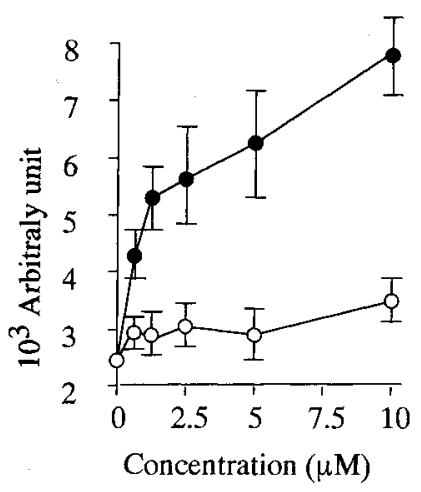

complex III causes the accumulation of ubisemiquinone, and to Qo center causes accumulation of ubiquinol. Ubisemiquinone is regarded as a direct electron donor for superoxide formation ${ }^{22)}$. AA is a well known Qi center inhibitor ${ }^{23)}$. UK-2A penetrated into the cells and inhibited mitochondrial electron transport as shown in Fig. 2 and 3, but it did not stimulate ROS generation. These results suggested that the binding site of UK-2A in mitochondrial complex III is not identical to that of AA. Due to its different blocking way in electron transport chain, UK-2A might not accumulate ubisemi-
(B)

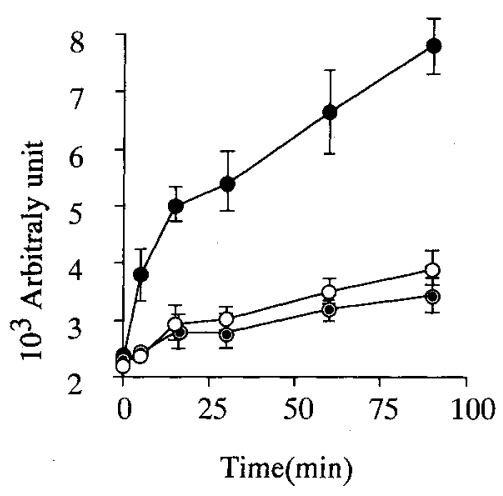

quinone radical, a electron donor to molecular oxygen. Examination of the inhibitory mechanism of UK-2A with isolated complex III is currently underway in our laboratory.

\section{Acknowledgments}

We wish to express our sincere gratitude to Dr. Hideto MryoshI, Graduate school of agriculture, Kyoto university, for helpful discussions. 


\section{References}

1) Ueki, M.; Kbe, M. Hanafi, K. Shibata, T. Tanaka \& M. Taniguchi: UK-2A, B, C and D, novel antifungal antibiotics from Streptomyces sp. 517-02. I. Fermentation, isolation and biological properties. J. Antibiotics 49: 639 643, 1996

2) Hanafi, M.; K. Shibata, M. Ueki \& M. Taniguchi: UK-2A, B, C, and D, novel antifungal antibiotics from Streptomyces sp. 517-02. II. Structure elucidation. J. Antibiotics 49: 1095 1100, 1996

3) Ueki, M.; M. Hanafi, J. Fujl, O. Sakanaka, K. InUma, M. UeKi \& M. TANiguchi: UK-2A, B, C, and $\mathrm{D}$, novel antifungal antibiotics from Streptomyces $\mathrm{sp}$. 517-02. III. Absolute configuration of an antifungal antibiotic, UK-2A, and consideration of its conformation. J. Antibiotics 51: 1113 1116, 1998

4) Ueki, M. \& M. TaniguchI: The mode of action of UK-2A and UK-3A, novel antifungal antibiotics from Streptomyces sp. 517-02. J. Antibiotics 50: 1052 1057, 1997

5) Daun, G.; P. C. Bohni \& G. Schatz: Import of proteins into mitochondria. J. Biol. Chem. 257: $13028 \sim 13033,1982$

6) Wolvetang, E. J.; K. L.Johnson, K. Krauer, S. J. RALPH \& A. W. LINNANE: Mitochondrial respiratory chain inhibitors induce apoptiosis. FEBS Lett. 339: $40 \sim 44,1994$

7) Hagar, H.; N. Ueda \& S. V. ShaH: Role of reaqctive oxygen metabolites in DNA damage and cell death in chemical hypoxic injury to LLC-PK1 cells. Am. J. Physiol. 271: F209 F215, 1996

8) Kaushal, G. P.; N. Ueda \& S. V. ShaH: Role of caspases (ICE/CED 3 proteases ) in DNA damage and cell death in response to a mitochondrial inhibitor, antimycin A. Kidney Int. 52: 438 445, 1997

9) Matthew, G. V. H.; N. S. Chandel, E. K. Williamson, P. T. Schumacker \& C. B. Thompson: $\mathrm{Bcl}-\mathrm{X}_{\mathrm{L}}$ regulates the membrane potential and volume homeostasis of mitochondria. Cell 91: 627 637, 1997

10) Ueda, N.; G. P. Kaushal, X. Hong \& S. V. Shah: Role of enhanced ceramide generation in DNA damage and cell death in chemical hypoxic injury to LLC-PK 1 cells. Kidney Int. 54: $399 \sim 406,1998$

11) Mosmann, T.: Rapid colorimetric assay for cellular growth and survival: application to proliferation and cytotoxicity assays. J. Immunol. Method. 65: 55 63, 1983
12) Walker, P. D. \& S. V. Shah: Hydrogen peroxide cytotoxicity in LLC-PK 1 cells; A role for iron. Kidney Int. 40: 891 898, 1991

13) Hertel, C.; S. J. Coulter \& J. P. Perkins: The involvement of cellular ATP in receptor mediated internalization of epidermal growth factor and hormone-induced internalization of $\beta$-adrenergic receptors. J. Biol. Chem. 261: 5974 5980, 1986

14) Nguyen, V. T.; M. Morange \& O. Bensaude: Firefly luciferase luminescence assays using scintillation counters for quantitation in transfected mammalian cells. Anal. Biochem. 171: 404 408, 1988

15) Carter, W. O.; P. K. Narayanan \& J. P. Robinson: Intracelluylar hydrogen peroxide and superoxide anion detection in endothelial cells. J. Leukocyte Biol. 55: $253 \sim 258,1994$

16) UEDA, N. \& S. V. SHAH: Role of intracellular calsium in hydrogen peroxide-induced rejnal tubular cell injury. Am. J. Physiol. 263: F214 F221, 1992

17) Venkatachalam, M.; Y. J. Patel, J. I. Kreisberg \& J. M. WeInBERG: Energy thresholds that determine membrane integrity and injury in a renal epithelial cell line (LLC-PK1). Relationships to phospholipid degradation and unesterified fatty acid accumulation. J. Clin. Invest. 81: $745 \sim 758,1988$

18) Halliwell, B. \& J. M. C. Gutteridge: Free radicals and catalytic metal ions in human disease: an over view. Methods Enzymol. 186: 1 85, 1990

19) Halliwell, B. \& J. M. C. GutTeridge: Free radicals in biology and medicine, Clarendon Press, Oxford, 1989

20) Shulze-Osthoff, K.; R. Beyaert, V. Vandevoorde, G. Haegeman \& W. Fiers: Depletion of the miotochondrial electron transport abrogates the cytotoxic and gene-inductive effects of TNF. EMBO J. $12: 3095 \sim 3104,1993$

21) Hagar, H.; N. Ueda \& S. V. Shah: Endonuclease induced DNA damage and cell death in chemical hypoxic injury to LLC-PKl cells. Kidney Int. 49: $355 \sim 361,1996$

22) Turrens, J. F.; A. Alexandre \& A. L. Lehninger: Ubisemiquinone is the electron donor for superoxide formation by complex III of heart mitochondria. Arch. Biochem. Biophys. 237: 408 414, 1985

23) Trumpower, B. L.: The protonmotive Q cycle energy trunsduction by coupling of proton translocation to electron transfer by the cytochrome bcl complex. J. Biol. Chem. 265: 11409 11412, 1990 